\title{
Association of pre-treatment radiographic characteristics of calcaneal fractures on patient-reported outcomes
}

\author{
Georgios Alexandridis ${ }^{1}$ (D) - Amy C. Gunning ${ }^{1,2} \cdot$ Ger D. J. van Olden $^{3} \cdot$ Egbert-Jan M. M. Verleisdonk $^{2}$ • \\ Michiel J. M. Segers ${ }^{4} \cdot$ Luke P. H. Leenen $^{1}$
}

Received: 14 May 2017 / Accepted: 18 February 2018 / Published online: 17 March 2018

(C) The Author(s) 2018

\begin{abstract}
Purposes Calcaneal fractures are known to influence patients' quality of life negatively. The type of calcaneal fracture might have a relation with the patient outcome. To inform patients in an early stage on how their calcaneal fracture may affect their lives, knowledge of the fracture characteristics is necessary. This study evaluates the association of type of calcaneal fracture, measurement of conventional radiograph angles, and the Sanders classification with patient-reported outcomes.

Material and methods This is a retrospective study based on a prospective trauma database including all patients aged 16 years or older with a calcaneal fracture admitted in one of the participating trauma level I or II hospitals. Patients, trauma, and fracture characteristics were collected. The conventional radiographs were evaluated in which type of fracture, and Böhler's, Gissane's, and calcaneal compression angles were determined. Also, the CT images were classified according to Sanders. In addition, displaced intra-articular calcaneal fractures were separately analyzed. A questionnaire was sent to the included patients that consisted of the EQ-6D, patient-specific characteristics, satisfaction with foot appearance and wearable shoe range, complications, and capability to work.

Results A total of 396 patients with 442 calcaneal fractures were eligible for follow-up. Two hundred fifteen patients with 246 calcaneal fractures participated. Patients with a calcaneal fracture into the talar surface reported a worse quality of life $(p=0.010)$, were less satisfied with their feet $(p<0.001)$, and had more complications $(p=0.001-0.006)$; extra-articular fractures had significantly opposite result. A negative Böhler's or calcaneal compression angle was related with unfavourable outcomes. Sanders classification was not related with any patient-reported outcome.

Conclusion Our study implies that patients with an intra-articular calcaneal fracture into the talar surface have a lower healthrelated quality of life, will be less satisfied with the outcome of their feet, and have more complications compared to patients with other type of calcaneal fractures. Furthermore, the Sanders classification was not associated with the patient-reported outcomes.
\end{abstract}

Keywords Calcaneal fracture $\cdot$ Sanders $\cdot$ Fracture $\cdot$ Calcaneum $\cdot$ Böhler's angle $\cdot$ Gissane's angle $\cdot$ Calcaneal compression angle $\cdot$ Patient-reported outcome $\cdot$ EQ-6D

Georgios Alexandridis

georgios.alexandridis@gmail.com

Amy C. Gunning

a.c.gunning@umcutrecht.nl

Ger D. J. van Olden

gdj.van.olden@meandermc.nl

Egbert-Jan M. M. Verleisdonk

ejverlei@diakhuis.nl

Michiel J. M. Segers

m.segers@antoniusziekenhuis.nl
Luke P. H. Leenen

1.p.h.leenen@umcutrecht.nl

1 Department of Surgery, University Medical Center Utrecht, Heidelberglaan 100, Suite: G04.228, 3584

CX Utrecht, The Netherlands

2 Department of Surgery, Diakonessenhuis Utrecht, Utrecht, The Netherlands

3 Department of Surgery, Meander Medical Center, Amersfoort, The Netherlands

4 Department of Surgery, St Antonius Hospital, Nieuwegein, The Netherlands 


\section{Introduction}

Calcaneal fractures occur with a reported incidence that varies from 11.5 to 13.7 per 100,000 persons per year [1-3]. These fractures are known, among orthopaedic healthcare providers, to influence gait and functional outcome negatively [4, 5]; moreover, these patients experience a lower quality of life than the general population [6-8].

To inform patients in an early stage (e.g., in the emergency department [ED]) on how their fracture could influence their lives and to customize the management of a patient, radiographic images may be evaluated. In order to evaluate patients' experiences with their outcome after a calcaneal fracture, patient-reported outcomes should be utilized [9]. Several studies have reported patient-reported outcomes [4, 7, 8]; however, most studies were performed in trauma level I patients. As a result, there is insufficient information in the current literature that includes trauma level II patients. Trauma level II centres have a different trauma population in comparison to trauma level I centres [10].

Moreover, the literature reports contrasting results on the predictive value of the measured angles in the conventional radiographs (e.g., Böhler's angle). On one hand, they are associated with functional outcome [11, 12]; on the other hand, they correlate poorly with the final outcome [13].

A prior study showed that $\mathrm{CT}$ image classification systems for calcaneal fractures have a predictive value on diseasespecific questionnaire outcomes [14]. An additional CT scan is performed when a patient is suspected for an intra-articular fracture or when better imaging is required to determine the treatment of the fracture. To classify these CT images, several classification systems have been developed. However, many of these classification systems are difficult to use because they classify calcaneal fractures in many groups [14].

The purpose of our study is to evaluate the association of type of calcaneal fracture, measurement of conventional radiograph angles (Böhler's, Gissane's, and calcaneal compression angles), and the Sanders classification with patientreported outcomes (i.e., health-related quality of life, calcaneal-related complications, patients' satisfaction, and capability to work).

\section{Material and methods}

\section{Hospital setting}

Four trauma centres participated in this study; one level I trauma centre (University Medical Center Utrecht) and three level II trauma centres (Meander Medical Center, Diakonessen Hospital, and St. Antonius Hospital). All four centres belong to the central trauma region in the Netherlands.

\section{Study design}

This is a retrospective study based on a prospective trauma database and a prospective patient-reported outcome evaluation that has been performed according to the criteria for evaluating health-related quality of life studies [15], and under the approval of the medical ethics committee of the University Medical Center Utrecht in the Netherlands.

\section{Study population}

We have included all patients aged 16 years and older at time of trauma and diagnosed with a calcaneal fracture. Two datasets were combined. In dataset \#1, the patients were selected from three different databases covering the years 2010 through 2012: the hospital databases, the regional trauma registry, and the Dutch National Medical Registration (DNMR) (www.dutchhospitaldata.nl). In these prospective databases, the calcaneal injuries were identified based on the descriptive diagnosis or International Classification of Diseases (ICD) [16]. We further added a dataset (dataset \#2) that contained patients from the DNMR of the trauma level I centre from 2000 through 2010; in this particular dataset, the patients diagnosed with a calcaneal fracture in another hospital were also included. Patients were registered more than once for the same injury event and were only included once.

\section{Data collection}

All data were extracted from the trauma registry and patients' medical record. We collected all patient demographic data such as gender, age, and comorbidities categorized according to the ASA physical status classification [17], psychiatric history, trauma mechanism, circumstances of trauma, Injury Severity Score (ISS) $[18,19]$, concomitant injuries, and the primary treatment of fracture.

\section{Radiographic characteristics}

All radiographic images were revised (performed by GA). The $\mathrm{CT}$ images and conventional radiographic images were used to determine the type of calcaneal fracture and whether there was a fracture into the anterior surface.

The CT images were classified with the Sanders classification [20]. The Sanders classification is used to categorize intra-articular fractures that involve the posterior facet of the calcaneus. The calcaneus can be divided into three parts by two fracture lines A and B. A third fracture, line C, separates the posterior facet of the calcaneus from the sustentacular fragment; consequently, there are potential four main articular fragments. Based upon these fracture lines, the Sanders classification is divided into four types (see Fig. 1): type I is a non- 
Fig. 1 Sanders classification. Line drawing of a semi-coronal image of the calcaneus showing all three fracture lines $(\mathrm{A}, \mathrm{B}$, and C) [Illustration made by GA]

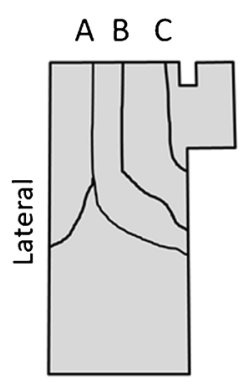

Type I
A B C

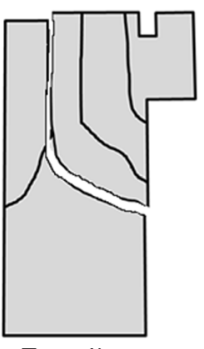

Type II

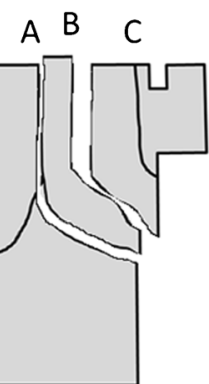

Type III
A B

C

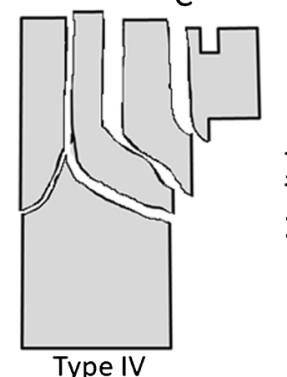

$\frac{\bar{\pi}}{\overline{0}}$ displaced fracture that is defined as less than $2 \mathrm{~mm}$ displacement, regardless of the number of fracture lines, type II, III, and IV are more than $2 \mathrm{~mm}$ displaced fractures, and have respectively one, two, or three and more fracture lines (See Fig. 2 for images of the four different types of calcaneal fractures that were classified according to Sanders). In general, it is assumed that the outcomes of the fractures are progressively worse with increasing type of Sanders classification [14].

In the conventional lateral radiographs, three angles were measured. Böhler's angle (Fig. 3a), also known as the tuberjoint angle, is the angle formed by two intersecting lines: a line between the highest point of the posterior facet to the highest point of the anterior surface, and a line connecting the highest point of the posterior tuberosity of the calcaneus and the posterior facet. Böhler's angle normal values in the uninjured population have been reported as a mean angle of $36^{\circ}$ (standard deviation $4^{\circ}$, range 25 to $49^{\circ}$, and the normal range that incorporates $95 \%$ of the subjects is 28 to $45^{\circ}$ ) [21]. In line with the study of Loucks et al. (1999), the measurements were divided in four predefined groups [11].

Gissane's crucial angle (Fig. 3b) is formed by the line from the calcaneal sulcus to the tip of the anterior surface of the
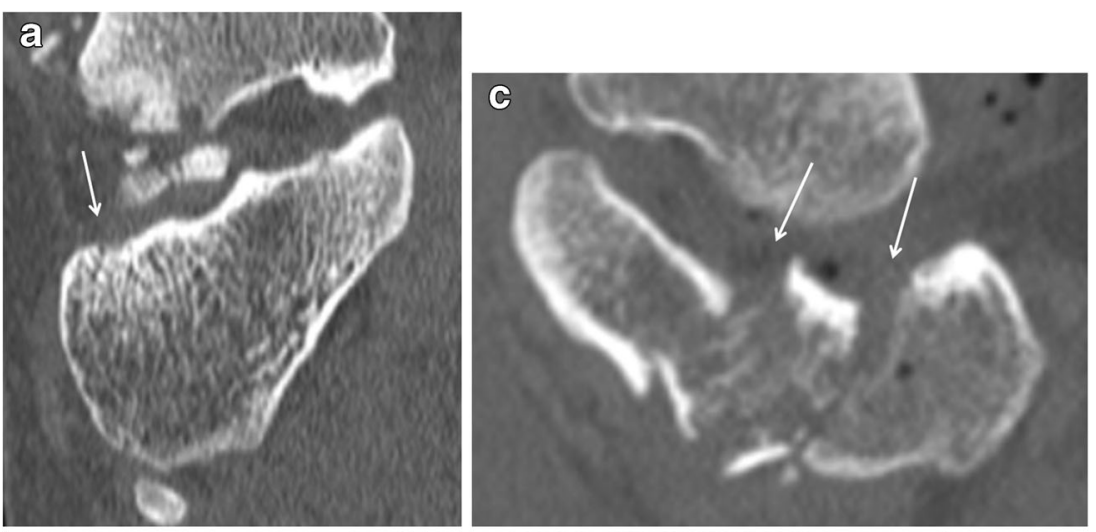

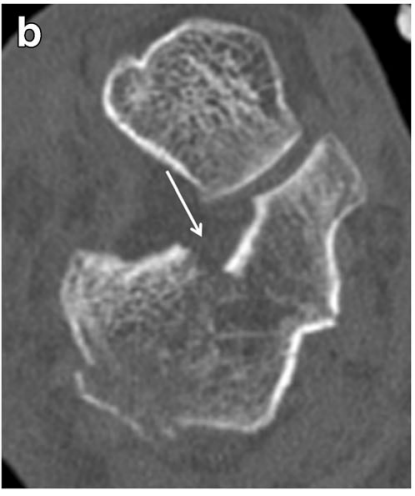

Fig. 2 (Semi)-coronal CT images of calcaneal fractures classified in accordance to the Sanders classification. The white arrow points to the fracture line(s). In parentheses, respectively, the pre-treatment angle versus finale angle. a Type I. Non-operatively treated. Böhler's angle (38 vs. $\left.38^{\circ}\right)$, Gissane's angle (122 vs. $\left.126^{\circ}\right)$, and calcaneal compression angle (32 vs. $36^{\circ}$ ). b Type II. Operatively treated with open reduction and internal plate fixation. Böhler's angle (17 vs. $\left.41^{\circ}\right)$, Gissane's angle (103 vs. $\left.108^{\circ}\right)$, and calcaneal compression angle (16 vs. $\left.40^{\circ}\right)$. c Type III. Operatively treated with open reduction and screw fixation. Böhler's angle (7 vs. $-14^{\circ}$ ), Gissane's angle (125 vs. $\left.109^{\circ}\right)$, and calcaneal compression angle $\left(18\right.$ vs. $\left.23^{\circ}\right)$. d Type IV. Operatively treated with open reduction and internal plate fixation. Böhler's angle (3 vs. $\left.2^{\circ}\right)$, Gissane's angle (139 vs. $128^{\circ}$ ), and calcaneal compression angle (30 vs. $42^{\circ}$ ) 

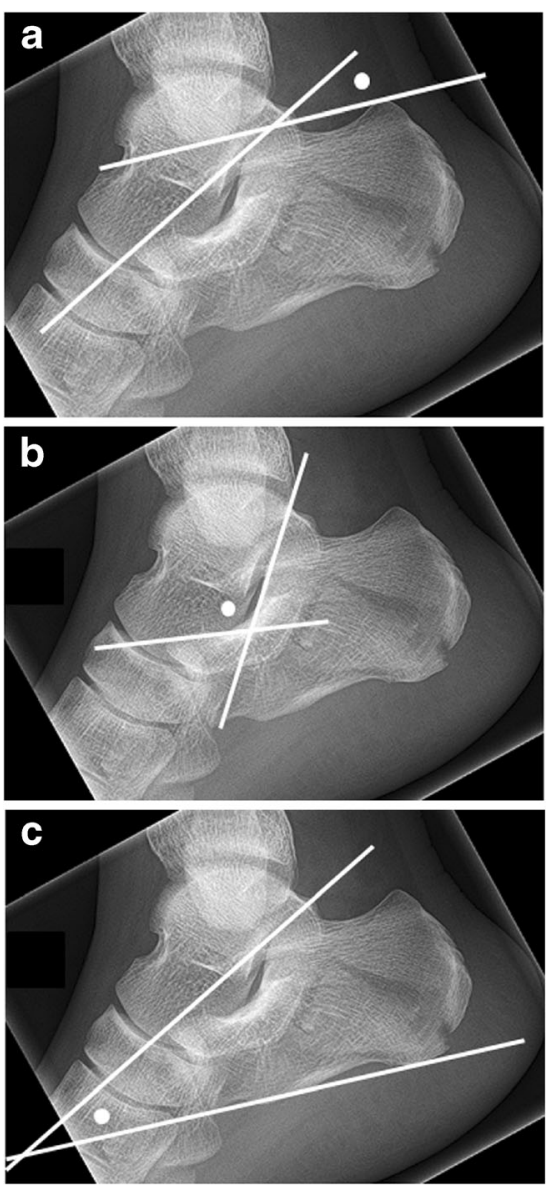

Fig. 3 Calcaneal angles in the conventional radiographs. a Böhler's angle (dot is the measured angle in this image and is $27^{\circ}$ ). b Gissane's angle (dot is the measured angle in this image and is $\left.114^{\circ}\right)$. $\mathbf{c}$ Calcaneal compression angle (dot is the measured angle in this image and is $29^{\circ}$ )

calcaneus, and the posterior facet. This angle was divided in three predefined groups based upon the normal values for Gissane's angle (mean 123 to $127^{\circ}$, with a standard deviation 6 to $8^{\circ}$, and a range from 108 to $138^{\circ}$ ) [22, 23].

The calcaneal compression angle (Fig. 3c) is created from two intersecting lines: a line between the highest point of the posterior facet and the anterior surface, and a line in the plane of the inferior surface of the calcaneus. The normal values for calcaneal compression angles (mean is $31^{\circ}$, with a standard deviation of $4^{\circ}$, and a range from 24 to $44^{\circ}$ ) were used to divide the measurements in three predefined groups [23].

\section{Outcomes}

Health-related quality of life is our primary outcome. Currently, there is no specific validated patient-reported outcome measurement available for foot and ankle injuries. One of the most used instruments in trauma care is the EQ-5D. The EQ-5D is a standardized generic measure of health-related quality of life whose validity, reliability, and responsiveness have been tested in studies for other extremity morbidities [24-30]. We have used the EQ-6D that is an extended version of the EQ-5D questionnaire and has an additional question addressing the cognitive function $[29,30]$.

The EQ-6D consists of six dimensions: "mobility", "selfcare", "usual activities", "pain / discomfort", "depression / anxiety", and "cognition". These dimensions have three levels of response: no problems, moderate problems, and severe problems. The EQ-5D index score can be calculated based upon the levels of response of the dimensions [31]. With the exception of the dimension cognition, because there is no validated tariff for the EQ-6D [31].

In general, health-related quality of life is influenced by various patient-specific characteristics, such as current comorbidities and socio-economic status [32-34]. Therefore, we have added questions on these aspects. Socio-economic status was determined by the highest level of education a patient has received.

Furthermore, patients were asked how satisfied they were with the appearance of the affected foot and range of shoes they could currently wear. The study of Dawson et al. (2012) showed that these factors are important for a patients' satisfaction after foot and ankle surgery [35].

In addition, the patients were asked for their capability to work. Moreover, a question on whether they have experienced a complication was included. Based on their answer and on the medical records, we have determined whether it was a calcaneal-related complication. The calcaneal-related complications were divided into two groups: the early calcaneal-related complications that occurred within six weeks after trauma (i.e., wound infection, malalignment, or compartment syndrome) and late calcaneal-related complications that occurred six weeks after their trauma (i.e., wound infection, impingement of peroneal tendons, claw or hammer toes, or malunion).

\section{Follow-up}

The EQ-6D questionnaire with the additional questions was sent to all eligible patients, along with an informed consent form. We have contacted the general practitioner on the whereabouts of patients that did not respond on our request to fill out the questionnaire; four weeks after the initial sentout of the questionnaire, a reminder was sent to all non-responders. The patients in dataset \#2 were also contacted by phone after another four weeks to collect missing data from participating patients and to ask non-responders one more time to participate in the study (performed by GA).

\section{Statistical analysis}

A descriptive analysis was performed to compare patient, trauma, and fracture characteristics. We have analyzed 
the total included population; in addition, a subanalysis was performed of the patients with a displaced intraarticular calcaneal fracture (DIACF) determined by CT imaging (Sanders II to IV) because it might be helpful to stratify this subgroup in order to inform patients more accurately.

Multiple patients had bilateral fractures; these patients were categorized into the group with the worst type of fracture. An open fracture was considered worse than a closed fracture. The highest Sanders type in intra-articular fractures was considered worse than other types of fractures, when Sanders classification was not applicable or there was no intraarticular fracture into the posterior facet than anterior surface involvement was considered worse than extra-articular. In the case of bilateral calcaneal fractures with the same Sanders type, the patient was categorized in the group with the lowest Böhler's angle.

To compare categorical variables, the chi-square test was used, and in the case of continuous variables, the Student's $T$ or Mann-Whitney $U$ tests were used. Furthermore, a linear regression analysis was performed to examine the relationship between the conventional radiograph angles and the EQ-5D index score.

The Dutch tariff for the calculation of the EQ-5D index score was used because there is no international validated tariff for the EQ-6D [31]. A difference of $\geq 0.032$ points between two EQ-5D index scores is a clinically relevant difference [31].

A $p$ value $<0.05$ was considered statistically significant and all data were analyzed with SPSS version 20.0 (IBM Corp., Armonk, NY), for Windows.

\section{Results}

\section{Study population}

A total of 446 patients who sustained a calcaneal fracture were identified in the databases. As demonstrated in Fig. 4, a total of 215 patients with 246 calcaneal fractures participated in this study. Before we have sent the questionnaire for a second time to the non-responders, the general practitioner was contacted for the whereabouts of the patients. The baseline patients, trauma, and fracture characteristics are outlined in Table 1. The mean age of the participants at time of trauma was 45 years and $64 \%$ was male. Approximately $50 \%$ had an isolated calcaneal fracture. The most common cause of the injury was fall from height from $1.5 \mathrm{~m}$ or higher, followed by a simple fall from less than $1.5 \mathrm{~m}$. The majority $(65 \%)$ of the fractures were into the talar surface of the calcaneus. On CT image, $65 \%$ of the fractures were a Sanders type II or III fracture. The primary treatment was non-operative in 119 cases; the other 125 fractures were treated operatively, of which 103 with open reduction and internal fixation, 15 with percutaneous reduction and fixation. One patient had subtalar arthrodesis, and in six patients, the operation technique was not described. In two cases, the treatment was not mentioned.

The follow-up characteristics are outlined in Table 2. The mean follow-up time of the participants was 62 months. The mean age at follow-up was 50 years. Approximately $40 \%$ were ASA II or III and $15 \%$ had a psychiatric history.
Fig. 4 Flowchart of enrolled patients

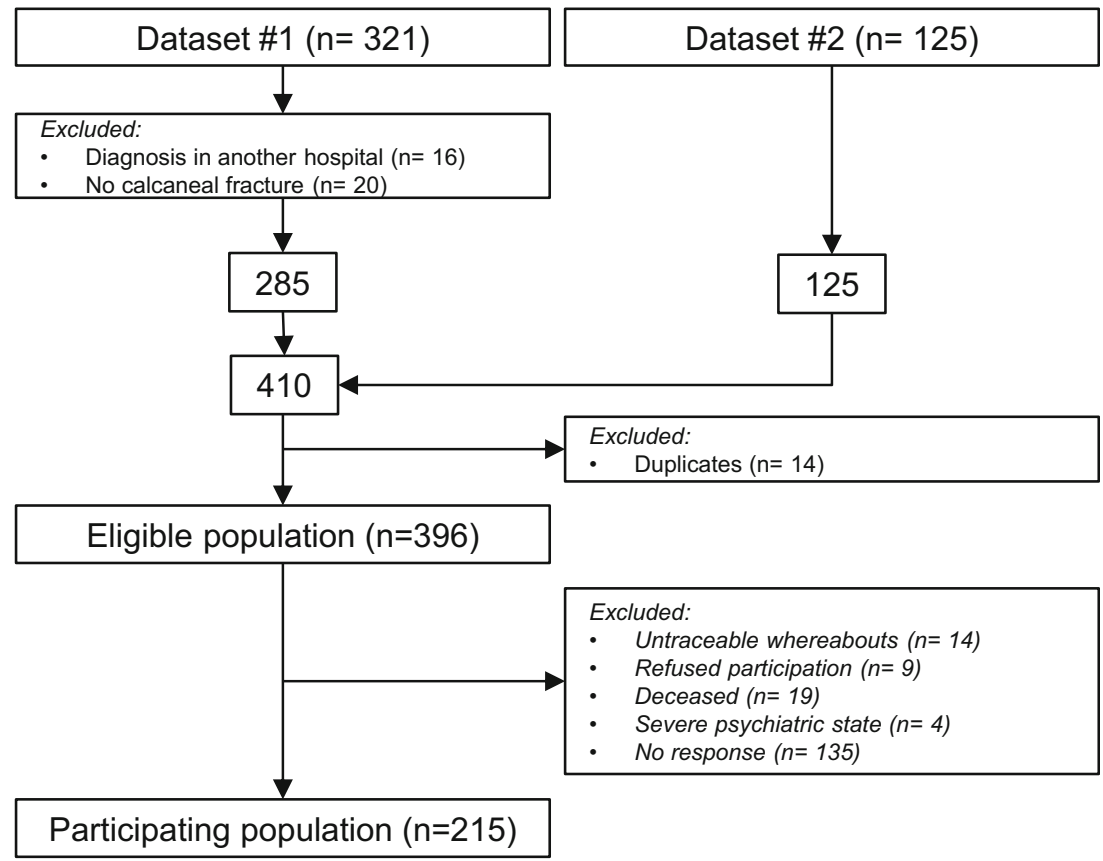


Table 1 Baseline characteristics

\begin{tabular}{|c|c|c|c|c|}
\hline & \multicolumn{2}{|l|}{ Total } & \multicolumn{2}{|c|}{ DIACF-only } \\
\hline & Eligible & Participating & Eligible & Participating \\
\hline Number of patients & 396 & 215 & 180 & 117 \\
\hline Age at trauma in years $* \|$ & $45(17)$ & $45(16)$ & $43(15)$ & $45(15)$ \\
\hline $\mathrm{Male}^{\dagger}$ & $245(62)$ & $138(64)$ & $125(69)$ & $80(68)$ \\
\hline Psychiatric history before trauma ${ }^{\dagger} \|$ & $61(15)$ & $29(14)$ & $31(17)$ & $15(13)$ \\
\hline Injury severity score ${ }^{\ddagger}$ & $4(4-5)$ & $4(4-8)$ & $4(4-8)$ & $4(4-8)$ \\
\hline Injury severity score $\geq 16^{\dagger}$ & $34(4)$ & $19(9)$ & $18(10)$ & $11(9)$ \\
\hline \multicolumn{5}{|l|}{ Associated injuries ${ }^{\dagger}$} \\
\hline No associated injuries & $237(60)$ & $116(54)$ & $100(56)$ & $62(53)$ \\
\hline Only lower limb associated injuries & $48(12)$ & $29(14)$ & $20(11)$ & $14(12)$ \\
\hline Only one other associated injury & $24(6)$ & $17(8)$ & $16(9)$ & $12(10)$ \\
\hline Multiple injuries & $87(22)$ & $53(25)$ & $44(24)$ & $29(25)$ \\
\hline \multicolumn{5}{|l|}{ Mechanism of trauma ${ }^{\dagger}$} \\
\hline Fall from height $\geq 1.5 \mathrm{~m}$ & $182(46)$ & $98(46)$ & $109(61)$ & $64(55)$ \\
\hline Simple fall $<1.5 \mathrm{~m}$ & $100(25)$ & $49(23)$ & $42(23)$ & $29(25)$ \\
\hline Crush & $12(3)$ & $9(4)$ & $1(1)$ & $1(1)$ \\
\hline Motor vehicle accident & $49(12)$ & $31(14)$ & $21(12)$ & $17(15)$ \\
\hline Sports/leisure & $12(3)$ & $6(3)$ & $5(3)$ & $4(3)$ \\
\hline Blast trauma & $3(1)$ & $3(1)$ & $1(1)$ & $1(1)$ \\
\hline Inversion trauma & $26(7)$ & $13(6)$ & $0(0)$ & $0(0)$ \\
\hline Other or unknown & $12(3)$ & $6(3)$ & $1(1)$ & $1(1)$ \\
\hline Bilateral calcaneal fracture $^{\dagger}$ & $46(11)$ & $31(14)$ & $30(17)$ & $22(19)$ \\
\hline Number of calcaneal fractures ${ }^{\dagger}$ & 442 & 246 & 210 & 139 \\
\hline Open calcaneal fracture ${ }^{\dagger}$ & $35(8)$ & $24(10)$ & $18(9)$ & $14(10)$ \\
\hline \multicolumn{5}{|l|}{ Anterior surface fracture involvement ${ }^{\dagger \S}$} \\
\hline Yes $^{\S}$ & $189(43)$ & $118(48)$ & $131(62)$ & $84(60)$ \\
\hline $\mathrm{No}^{\S}$ & $212(48)$ & $100(41)$ & $79(38)$ & $55(40)$ \\
\hline Undeterminable & $41(9)$ & $28(11)$ & $0(0)$ & $0(0)$ \\
\hline \multicolumn{5}{|l|}{ Type of calcaneal fracture ${ }^{\dagger \S}$} \\
\hline Fracture into talar surface ${ }^{\S}$ & $254(58)$ & $164(65)$ & $200(95)$ & $134(96)$ \\
\hline Isolated anterior surface fracture & $55(12)$ & $33(13)$ & $2(1)$ & $1(1)$ \\
\hline Isolated extra-articular fracture ${ }^{\S}$ & $121(27)$ & $41(17)$ & $8(4)$ & $4(3)$ \\
\hline Undeterminable & $12(3)$ & $8(3)$ & $0(0)$ & $0(0)$ \\
\hline \multicolumn{5}{|l|}{$\mathrm{CT}$ imaging ${ }^{\dagger}$} \\
\hline Sanders type I & $13(3)$ & $5(2)$ & $0(0)$ & $0(0)$ \\
\hline Sanders type II & $103(23)$ & $63(26)$ & $103(49)$ & $63(45)$ \\
\hline Sanders type III ${ }^{\S}$ & $68(15)$ & $51(21)$ & $68(32)$ & $51(37)$ \\
\hline Sanders type IV & $28(6)$ & $19(8)$ & $28(13)$ & $19(14)$ \\
\hline Isolated extra-articular fracture ${ }^{\S}$ & $41(9)$ & $16(7)$ & $6(3)$ & $3(2)$ \\
\hline Isolated anterior surface fracture & $33(8)$ & $22(9)$ & $2(1)$ & $1(1)$ \\
\hline Not available ${ }^{\S}$ & $156(35)$ & $70(29)$ & $3(1)$ & $2(1)$ \\
\hline Primary operative treatment ${ }^{\dagger} \S \|$ & $173(39)$ & $125(51)$ & $132(63)$ & $96(73)$ \\
\hline
\end{tabular}

$D I A C F$ displaced intra-articular calcaneal fracture

*Mean (standard deviation)

$\dagger$ Number (percent)

$\ddagger$ Median (interquartile range)

$\S p<0.05$ in eligible versus participating total population

$\| p<0.05$ in eligible versus participating DIACF-only population 
Table 2 Follow-up characteristics and outcome results

\begin{tabular}{|c|c|c|}
\hline & Total & DIACF only \\
\hline Number of patients & 215 & 117 \\
\hline Follow-up time in months ${ }^{\dagger}$ & $62(35)$ & $60(32)$ \\
\hline Age in years ${ }^{\dagger}$ & $50(15)$ & $50(15)$ \\
\hline \multicolumn{3}{|l|}{ Comorbidities* } \\
\hline ASA I & $132(62)$ & $70(59)$ \\
\hline ASA II & $72(34)$ & $43(23)$ \\
\hline ASA III & $10(5)$ & $6(3)$ \\
\hline Psychiatric history* & $33(15)$ & $18(15)$ \\
\hline \multicolumn{3}{|l|}{ Educational status* } \\
\hline High & $58(27)$ & $27(23)$ \\
\hline Middle & $71(33)$ & $42(36)$ \\
\hline Low & $84(39)$ & $49(42)$ \\
\hline \multicolumn{3}{|c|}{ Satisfaction with wearable range of shoes* } \\
\hline Satisfied & $78(36)$ & $35(30)$ \\
\hline Moderately satisfied & $97(45)$ & $55(47)$ \\
\hline Unsatisfied & $39(18)$ & $28(24)$ \\
\hline Capable to work* & $182(85)$ & $99(84)$ \\
\hline EQ-5D index value ${ }^{\ddagger}$ & $0.81(0.78-0.90)$ & $0.78(0.69-0.84)$ \\
\hline Number of fractures & 246 & 128 \\
\hline \multicolumn{3}{|l|}{ Pre-treatment angles ${ }^{\ddagger}$} \\
\hline Böhler’s & $19(6-29)$ & $16(3-25)$ \\
\hline Gissane's & $110(100-117)$ & $109(100-116)$ \\
\hline Calcaneal compression & $27(20-32)$ & $25(18-30)$ \\
\hline \multicolumn{3}{|l|}{ Final angles ${ }^{\ddagger}$} \\
\hline Böhler's & $27(14-33)$ & $24(13-31)$ \\
\hline Gissane's & $108(100-117)$ & $108(101-117)$ \\
\hline Calcaneal compression & $27(23-33)$ & $27(23-32)$ \\
\hline \multicolumn{3}{|c|}{ Satisfaction with appearance of affected foot* } \\
\hline Satisfied & $133(54)$ & $55(41)$ \\
\hline Moderately satisfied & $81(33)$ & $58(44)$ \\
\hline Unsatisfied & $30(12)$ & $19(14)$ \\
\hline Amputation & $2(1)$ & $1(1)$ \\
\hline \multicolumn{3}{|c|}{ Calcaneal-related complication* } \\
\hline Before 6 weeks & $50(21)$ & $36(27)$ \\
\hline After 6 weeks & $64(26)$ & $44(34)$ \\
\hline
\end{tabular}

$D I A C F$ displaced intra-articular calcaneal fracture (Sanders type II to IV) *Number (percent of population)

$\dagger$ Mean (standard deviation)

$\neq$ Median (interquartile range)

\section{Association of fracture characteristics and patient-reported outcomes}

As demonstrated in Tables 3 and 4, Figs. 5 and 6, the type of calcaneal fracture is associated with several patient-reported outcomes. Patients with a fracture in the talar surface of the calcaneus reported the worst outcomes; these patients reported significantly more problems with washing or dressing themselves ("self-care"), walking ("mobility"), and experienced more pain or discomfort compared to the other fracture types. Consequently, these patients had a significantly lower EQ-5D index score $(p=0.010)$. Moreover, these patients were less satisfied with the appearance of their affected foot $(p=$ $0.001)$ and range of wearable shoes $(p=0.042)$. Also, these patients had more often early and late calcaneal-related complications (respectively, $p=0.001$ and $p=0.006$ ). In contrast, patients with an extra-articular fracture reported less often problems in the EQ-6D dimensions (see Fig. 4) compared to the other type of calcaneal fractures; as a result, they had a higher EQ-5D index score $(p=0.003)$. However, these patients reported noticeably more problems per EQ-6D dimension than the Dutch reference population. The patients who had a fracture line in the anterior surface had a lower EQ-5D index score $(p=0.046)$. This patient group further had more complications and was less satisfied with the appearance of their foot and wearable range of shoes.

\section{Association of radiographic characteristics and patient-reported outcome}

Böhler's angle before treatment was not associated to the EQ5D index score $(r=0.098, \beta=0.001, t=1.325, p=0.187)$. However, a negative Böhler's angle demonstrated to have worse outcome results, reflected in a lower EQ-5D index score $(p=0.006)$ and more early calcaneal-related complications $(p<0.001)$.

Gissane's angle was not related to the EQ-5D index score $(r=0.051, \beta<0.001, t=-0.110, p=0.913)$. A Gissane's angle of more than $135^{\circ}$ was associated with more early calcaneal-related complications $(p=0.004)$ and a poor satisfaction with the wearable range of shoes $(p=0.042)$.

The calcaneal compression angle was poorly correlated to the EQ-5D index score $(r=0.157, \beta=0.004, t=2.149, p=$ 0.033). Patients who had a negative calcaneal compression angle reported more problems in all six dimensions of the EQ-6D ( $p=0.001$ to 0.023$)$ that resulted in a substantial lower EQ-5D index score $(p=0.001)$.

The Sanders classification (type I to IV) was not associated with the EQ-5D index score $(p=0.215)$, or any of the other measured outcomes ( $p=0.109$ to 0.556 ).

\section{Patient-reported outcome in patients with DIACF (Sanders type II to IV)}

We performed an additional analysis of patients with a CT confirmed DIACF (Sanders type II to IV). None of the measured angles in the conventional radiographs (Böhler's, Gissane's, or calcaneal compression angle) showed to be associated with the EQ-5D index score ( $p=0.227$ to 0.790 ); nor was anterior surface fracture involvement $(p=0.503)$. Patients with a DIACF and a negative calcaneal compression angles 
Table 3 Patient-reported outcome results per type of fracture and Sanders classification

\begin{tabular}{|c|c|c|c|c|c|c|c|}
\hline & $\begin{array}{l}\text { Number of } \\
\text { patients* }\end{array}$ & $\begin{array}{l}\text { EQ-5D index } \\
\text { score }^{\ddagger}\end{array}$ & $\begin{array}{l}\text { Satisfied with } \\
\text { appearance of } \\
\text { affected foot }^{\dagger}\end{array}$ & $\begin{array}{l}\text { Calcaneal-related } \\
\text { complication before } \\
6 \text { weeks }^{\dagger}\end{array}$ & $\begin{array}{l}\text { Calcaneal-related } \\
\text { complication after } \\
6 \text { weeks }^{\dagger}\end{array}$ & $\begin{array}{l}\text { Capable } \\
\text { to } \text { work }^{\dagger}\end{array}$ & $\begin{array}{l}\text { Satisfied with } \\
\text { wearable range } \\
\text { of shoes }^{\dagger}\end{array}$ \\
\hline Type of calcaneal fracture & & $\S$ & $\S$ & $\S$ & $\S$ & & $\S$ \\
\hline Fracture into talar surface & $143(67)$ & $0.78(0.78-0.84)^{\S}$ & $76(46)^{\S}$ & $44(27)^{\S}$ & $53(33)^{\S}$ & $121(85)$ & $45(32)^{\S}$ \\
\hline Isolated anterior surface fracture & $32(15)$ & $0.81(0.78-1.00)$ & $21(64)$ & $3(9)$ & $6(18)$ & $25(78)$ & $11(34)$ \\
\hline Isolated extra-articular fracture & $34(16)$ & $0.95(0.80-1.00)^{\S}$ & $33(81)^{\S}$ & $3(7)^{\S}$ & $4(10)^{\S}$ & $30(91)$ & $21(62)^{\S}$ \\
\hline Undeterminable & $6(3)$ & $0.78(0.56-0.82)$ & $3(38)$ & $1(13)$ & $3(38)$ & $6(100)$ & $1(17)$ \\
\hline CT imaging & & & $\S$ & $\S$ & & & \\
\hline Sanders type I & $5(2)$ & $0.81(0.73-1.00)$ & $3(60)$ & $1(20)$ & $0(0)$ & $5(100)$ & $2(40)$ \\
\hline Sanders type II & $55(26)$ & $0.78(0.65-0.84)$ & $28(44)$ & $11(18)$ & $18(29)$ & $48(87)$ & $20(36)$ \\
\hline Sanders type III & $46(21)$ & $0.81(0.78-0.89)$ & $22(43)$ & $17(33)^{\S}$ & $19(37)$ & $36(80)$ & $13(29)$ \\
\hline Sanders type IV & $16(7)$ & $0.78(0.65-0.80)$ & $5(26)^{\S}$ & $8(42)^{\S}$ & $8(42)$ & $13(81)$ & $2(13)^{\S}$ \\
\hline Isolated extra-articular fracture & $10(5)$ & $0.84(0.66-1.00)$ & $10(63)$ & $3(19)$ & $3(19)$ & $8(89)$ & $5(50)$ \\
\hline Isolated anterior surface fracture & $21(10)$ & $0.81(0.58-1.00)$ & $11(50)$ & $3(14)$ & $6(27)$ & $16(76)$ & $5(24)$ \\
\hline Not available & $62(29)$ & $0.84(0.78-1.00)$ & $57(77)^{\S}$ & $8(11)^{\S}$ & $12(17)^{\S}$ & $56(90)$ & $31(50)^{\S}$ \\
\hline $\begin{array}{l}\text { Anterior surface fracture } \\
\text { involvement }\end{array}$ & & $\S$ & & $\S$ & $\S$ & & $\S$ \\
\hline Yes & $109(51)$ & $0.78(0.78-0.89)^{\S}$ & $55(47)^{\S}$ & $38(29)^{\S}$ & $45(37)^{\S}$ & $90(83)$ & $31(29)^{\S}$ \\
\hline No & $84(39)$ & $0.81(0.78-1.00)$ & $61(61)$ & $12(12)^{\S}$ & $17(17)^{\S}$ & $72(87)$ & $40(47)^{\S}$ \\
\hline Undeterminable & $22(10)$ & $0.81(0.78-0.85)$ & $17(61)$ & $7(23)$ & $12(39)$ & $20(91)$ & $7(35)$ \\
\hline
\end{tabular}

*Number (percent)

$\dagger$ Number of outcome with that result (percent with outcome result within category)

$\neq$ Median (interquartile range)

$\S p<0.05$

Table 4 Patient-reported outcome results per measured angles in the conventional radiographs

\begin{tabular}{|c|c|c|c|c|c|c|c|}
\hline & $\begin{array}{l}\text { Number of } \\
\text { patients* }\end{array}$ & $\begin{array}{l}\text { EQ-5D index } \\
\text { score }^{\ddagger}\end{array}$ & $\begin{array}{l}\text { Satisfied with } \\
\text { appearance of } \\
\text { affected foot }\end{array}$ & $\begin{array}{l}\text { Calcaneal-related } \\
\text { complication before } \\
6 \text { weeks }^{\dagger}\end{array}$ & $\begin{array}{l}\text { Calcaneal-related } \\
\text { complication after } \\
6 \text { weeks }^{\dagger}\end{array}$ & $\begin{array}{l}\text { Capable } \\
\text { to work }{ }^{\dagger}\end{array}$ & $\begin{array}{l}\text { Satisfied with } \\
\text { wearable range } \\
\text { of shoes }^{\dagger}\end{array}$ \\
\hline Pre-treatment Böhler's angle & & $\S$ & $\S$ & $\S$ & & $\S$ & \\
\hline$<0^{\circ}$ & $22(10)$ & $0.75(0.65-0.82)^{\S}$ & $9(35)^{\S}$ & $14(52)^{\S}$ & $11(41)$ & $13(59)^{\S}$ & $3(14)^{\S}$ \\
\hline $0-14^{\circ}$ & $42(20)$ & $0.78(0.78-0.89)$ & $21(44)$ & $11(23)$ & $12(25)$ & $36(88)$ & $14(33)$ \\
\hline $15-45^{\circ}$ & $112(53)$ & $0.81(0.78-1.00)^{\S}$ & $74(61)^{\S}$ & $21(17)$ & $29(24)$ & $97(87)$ & $46(41)$ \\
\hline$>45^{\circ}$ & $6(3)$ & $0.72(0.57-0.88)$ & $5(83)$ & $1(17)$ & $1(17)$ & $6(100)$ & $3(50)$ \\
\hline Undeterminable & $33(15)$ & $0.81(0.78-0.85)$ & $20(51)$ & $4(10)$ & $13(33)$ & $30(91)$ & $12(36)$ \\
\hline Pre-treatment Gissane's angle & & & & $\S$ & & & $\S$ \\
\hline$<95^{\circ}$ & $24(11)$ & $0.81(0.78-0.84)$ & $13(48)$ & $4(15)$ & $7(26)$ & $20(83)$ & $5(21)$ \\
\hline $95-135^{\circ}$ & $145(67)$ & $0.81(0.75-1.00)$ & $89(56)$ & $37(23)$ & $42(26)$ & $119(83)$ & $59(41)^{\S}$ \\
\hline$>135^{\circ}$ & $7(3)$ & $0.78(0.78-0.84)$ & $4(50)$ & $5(63)^{\S}$ & $2(25)$ & $7(100)$ & $0(0)^{\S}$ \\
\hline Undeterminable & $39(18)$ & $0.81(0.78-0.84)$ & $23(50)$ & $5(11)$ & $15(33)$ & $36(92)$ & $14(36)$ \\
\hline $\begin{array}{l}\text { Pre-treatment calcaneal } \\
\text { compression angle }\end{array}$ & & $\S$ & $\S$ & $\S$ & & & \\
\hline$<25^{\circ}$ & $64(30)$ & $0.78(0.65-0.84)^{\S}$ & $28(38)^{\S}$ & $24(32)^{\S}$ & $24(32)$ & $47(76)^{\S}$ & $16(25)^{\S}$ \\
\hline $25-45^{\circ}$ & $114(53)$ & $0.84(0.78-1.00)^{\S}$ & $79(64)^{\S}$ & $23(19)$ & $27(22)$ & $101(89)$ & $49(43)^{\S}$ \\
\hline$>45^{\circ}$ & $3(1)$ & $0.78(0.69-)$ & $2(50)$ & $0(0)$ & $1(25)$ & $3(100)$ & $1(33)$ \\
\hline Undeterminable & $34(16)$ & $0.81(0.78-0.85)$ & $20(50)$ & $4(10)$ & $14(35)$ & $31(91)$ & $12(35)$ \\
\hline
\end{tabular}

*Number (percent)

$\dagger$ Number of outcome with that result (percent with outcome result within category)

$¥$ Median (interquartile range)

$\S p<0.05$ 


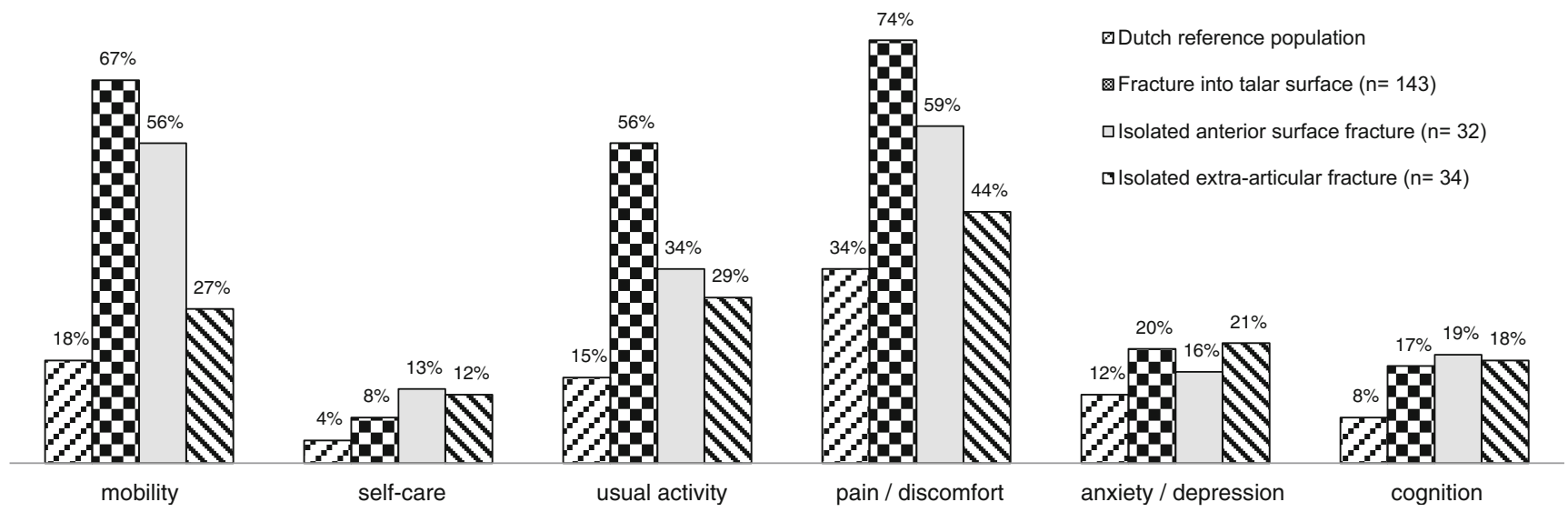

Fig. 5 Reported problems per dimension of the EQ-6D per type of fracture

were less satisfied with the appearance of their foot $(68 \%, p=$ $0.040)$; all the other measured angles were not associated with the outcomes ( $p=0.058$ to 0.865 ). Interestingly, patients who had anterior surface involvement and a DIACF experienced more early calcaneal-related complications $(36 \%, p=0.013)$ and more late calcaneal-related complications $(45 \%, p=$ $0.024)$; involvement of the anterior surface was not associated with any of the other outcome results ( $p=0.327$ to 0.630$)$.

\section{Discussion}

This study demonstrates that the type of fracture is related with outcomes such as the health-related quality of life, calcanealrelated complications, and satisfaction with the appearance of the foot and the shoes they can wear. Patients with fractures into the talar surface of the calcaneus report substantial unfavourable outcomes in comparison to the other type of fractures. In contrast, patients with extra-articular fractures report significantly better results. Patients with extra-articular fractures are in particular negatively affected in the EQ-6D dimensions "self-care", "usual activity", and "cognition". Possibly, a great proportion of patients with an extraarticular fracture are elderly that might have had a negative influence on the EQ-6D outcome; this could not be reduced from our presented data. The study of Hoeymans et al. (2005) on the health-related quality of life in the Dutch population shows that elderly patients report significantly more problems than younger patients in all six dimensions of the EQ-6D [33].

In addition, a negative Böhler's angle, a negative calcaneal compression angle, or a fracture into the anterior surface of the calcaneus is associated with worse patient outcomes. The literature reports contrasting results in the predictive value of the Böhler's angle [11-13, 36]. The studies from Loucks et al. (1999) and Persson et al. (2015) demonstrated that a negative Böhler's angle in patients with an intra-articular calcaneal fracture is negatively related to health-related quality of life outcome $[11,12]$. The results in this study do not support those findings. This could be due to different inclusion criteria, our study includes also patients with an open calcaneal fracture, and due to a different trauma level population, our study also includes patients from level II trauma centers. Including these patients may cause a greater heterogeneity of patients. Patients from the trauma level II have in general a less severe injury in comparison to trauma level I patients; while, patients with an open fracture likely meet more complications that might result in an unfavourable outcome. Furthermore, the inter-

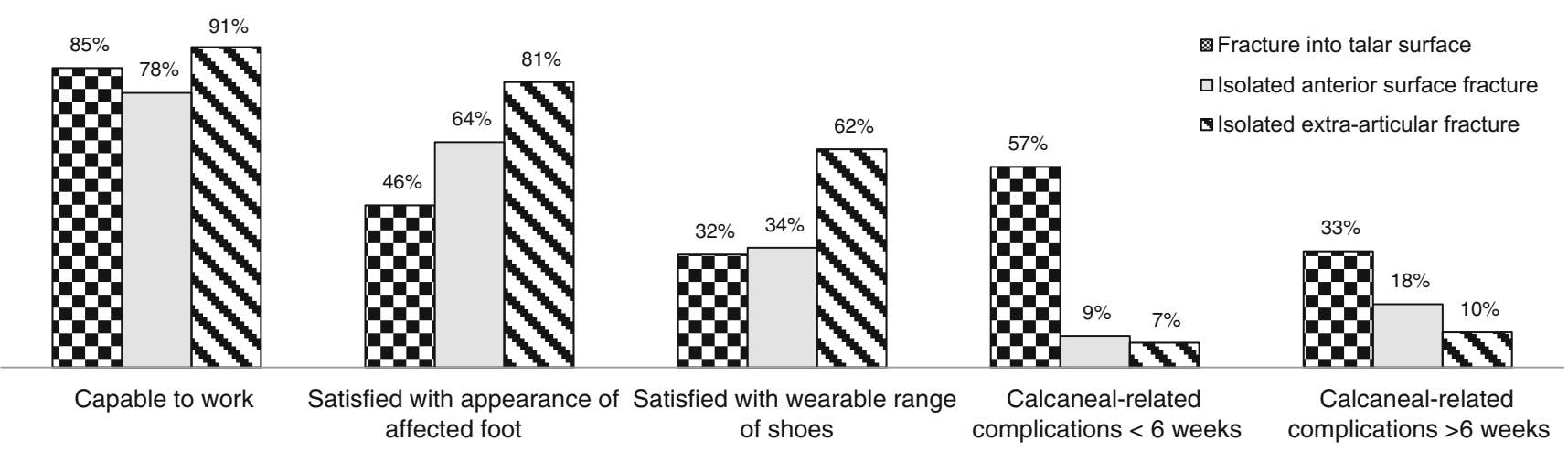

Fig. 6 Patient-reported outcome results per type of fracture 
and intra-observer reliability has been reported limited in several occasions [36-40]; therefore, the correct measurement of this angle is questionable. Therefore, we do not advise to use Böhler's angle for estimating the patientreported outcomes. Further investigation by means of a systematic review and meta-analysis may elaborate to which extent the Böhler's angle could be utilized.

In line with several studies on Gissane's angle, this angle does not appear to be related to final outcome [13, 41, 42]. Consequently, we do not recommend the measurement of this angle.

The Sanders classification is one of the most reported systems to classify intra-articular fractures in the posterior facet of the talar surface [13]. The literature showed that the interobserver and intra-observer reliability is poor to mediocre [37-39]. This study shows that the Sanders classification is not related to any of the patient-reported outcomes which indicate that the Sanders classification cannot be used to make reliable assumptions of the expected outcome.

In comparison with the study of Kinner et al. (2010), we did not demonstrate a significant difference in health-related quality of life in patients who had a DIACF and a fracture in the anterior surface of the calcaneus [43]. Moreover, our complication rate was twice as high. A possible explanation is that Kinner et al. (2010) excluded patients that might influence the results, for example patient, who did not have post-operative CT imaging, patients older than 65 years, or patients with a bilateral fracture [43].

Alike most retrospective studies, data collection was limited by information that was not or incorrectly recorded. Less than $10 \%$ of data was missing in our study. Moreover, not all type of fractures could be classified according to the Sanders classification because $\mathrm{CT}$ images were not available for all the included patients. The follow-up duration has a wide range, which could influence the results; the longer the follow-up, the more likely it is that other comorbidities are introduced that might influence the outcome [44]. In addition, loss to followup might bias the results in cohort studies [45]. The patients that participated in our study had significantly less often an extra-articular fracture; however, the baseline characteristics between the eligible and the participating population were more or less the equal. Therefore, though there is a significant loss to follow-up in this study population, the bias is expected to be minimal.

Due to the inclusion of patients admitted in level I and II trauma centers belonging to the same trauma region, these results represent a reliable reflection from the demographics and outcome of patients with a calcaneal fracture in a regionalized trauma population and allow us to generalize the results.

In conclusion, the study results demonstrate that patients with an intra-articular calcaneal fracture into the talar surface have a lower health-related quality of life, will be less satisfied with the outcome of their feet, and have more complications compared to patients with other types of calcaneal fractures. In contrast, extra-articular fractures have significantly favorable results. The Sanders classification was not associated with patient-reported outcomes. Furthermore, we do not recommend the measurement of angles in conventional radiographs to inform patients on the possible outcome of their lives because of the poor relationship with patient-reported outcome results and the limited reliability of accurate measurement of these angles.

\section{Compliance with ethical standards}

Conflict of interest The authors declare that they have no conflict of interest.

Ethical approval This article does not contain any studies with human participants or animals performed by any of the authors.

Informed consent Informed consent was obtained from all individual participants included in the study.

Open Access This article is distributed under the terms of the Creative Commons Attribution 4.0 International License (http:// creativecommons.org/licenses/by/4.0/), which permits unrestricted use, distribution, and reproduction in any medium, provided you give appropriate credit to the original author(s) and the source, provide a link to the Creative Commons license, and indicate if changes were made.

\section{References}

1. Brauer CA, Manns BJ, Ko M, Donaldson C, Buckley R (2005) An economic evaluation of operative compared with nonoperative management of displaced intra-articular calcaneal fractures. J Bone Joint Surg Am 87(12):2741-2749

2. Court-Brown CM, Caesar B (2006) Epidemiology of adult fractures: a review. Injury 37(8):691-697

3. Mitchell MJ, McKinley JC, Robinson CM (2009) The epidemiology of calcaneal fractures. Foot (Edinb) 19(4):197-200

4. Van Hoeve S, de Vos J, Verbruggen JP, Willems P, Meijer K, Poeze M (2015) Gait analysis and functional outcome after calcaneal fracture. J Bone Joint Surg Am 97(22):1879-1888

5. O’Brien J, Buckley R, McCormack R, Pate G, Leighton R, Petrie D, Galpin R (2004) Personal gait satisfaction after displaced intraarticular calcaneal fractures: a 2-8 year followup. Foot Ankle Int 25(9):657-665

6. Alexandridis G, Gunning AC, Leenen LP (2015) Patient-reported health-related quality of life after a displaced intra-articular calcaneal fracture: a systematic review. World J Emerg Surg 10:62

7. Van Tetering EA, Buckley RE (2004) Functional outcome (SF-36) of patients with displaced calcaneal fractures compared to SF-36 normative data. Foot Ankle Int 25(10):733-738

8. Buckley R, Tough S, McCormack R, Pate G, Leighton R, Petrie D, Galpin R (2002) Operative compared with nonoperative treatment of displaced intra-articular calcaneal fractures: a prospective, randomized, controlled multicenter trial. J Bone Joint Surg Am 84A(10):1733-1744 
9. Weldring T, Smith SMS (2013) Patient-reported outcomes (PROs) and patient-reported outcome measures (PROMs). Health Serv Insights 6:61-68

10. Alexandridis G, Gunning AC, van Olden GDJ, Verleisdonk EJMM, Segers MJM, Leenen LPH (2017) A trauma system wide evaluation of the demographic, injury and fracture characteristics of patients with calcaneal fractures: a comparison of trauma level I and II centers. Clin Res Foot Ankle 5:2

11. Loucks C, Buckley R (1999) Bohler's angle: correlation with outcome in displaced intra-articular calcaneal fractures. J Orthop Trauma 13(8):554-558

12. Persson J, Peters S, Haddadin S, O'Loughlin PF, Krettek C, Gaulke $R$ (2015) The prognostic value of radiologic parameters for longterm outcome assessment after an isolated unilateral calcaneus fracture. Technol Health Care 23(3):285-298

13. Schepers T, Ginai AZ, Mulder PG, Patka P (2007) Radiographic evaluation of calcaneal fractures: to measure or not to measure. Skelet Radiol 36(9):847-852

14. Rubino R, Valderrabano V, Sutter PM, Regazzoni P (2009) Prognostic value of four classifications of calcaneal fractures. Foot Ankle Int 30(3):229-238

15. Efficace F, Bottomley A, Osoba D, Gotay C, Flechtner H, D'haese $S$ et al (2003) Beyond the development of health-related quality-oflife (HRQOL) measures: a checklist for evaluating HRQOL outcomes in cancer clinical trials - does HRQOL evaluation in prostate cancer research inform clinical decision making? J Clin Oncol 21(18):3502-3511

16. Lcd-9-cm: International Classification of Diseases, 9th Revision, Clinical Modification (1996) Salt Lake City, Utah: Medicode

17. American Society of Anesthesiologists (1963) New classification of physical status. Anesthesiology 24:III

18. Association for the Advancement of Automotive Medicine: The Abbreviated Injury Scale 1990 Revision-Update 98 Barrington (1998) IL: Association for the Advancement of Automotive Medicine

19. Baker SP, O’Neill B, Haddon W Jr, Long WB (1974) The injury severity score: a method for describing patients with multiple injuries and evaluating emergency care. J Trauma 14(3):187-196

20. Sanders R (1992) Intra-articular fractures of the calcaneus: present state of the art. J Orthop Trauma 6(2):252-265

21. Wilmott H, Stanton J, Southgate C (2012) Böhler's angle - what is normal in the uninjured British population? Foot Ankle Surg 18: $187-189$

22. Sengodan VC, Amruth KH, Karthikeyan (2012) Böhler's and Gissane angles in the Indian population. J Clin Imaging Sci 2:77

23. Shoukry FA, Aref YK, Sabry AAE (2012) Evaluation of the normal calcaneal angles in Egyptian population. Alexandria J Med 48(2): 91-97

24. Harrison MJ, Davies LM, Bansback NJ, Ingram M, Anis AH, Symmons DP (2008) The validity and responsiveness of generic utility measures in rheumatoid arthritis: a review. J Rheumatol 35(4):592-602

25. Honkavaara N, Al-Ani AN, Compenfeldt P, Ekström W, Hedström M (2016) Good responsiveness with EuroQol 5-dimension questionnaire and short form (36) health survey in 20-69 years old patients with a femoral neck fracture: a 2-year prospective follow-up study in 182 patients. Injury 47(8):1692-1697

26. Hung MC, Lu WS, Chen SS, Hou WH, Hsieh CL, Wang JD (2015) Validation of the EQ-5D in patients with traumatic limb injury. J Occup Rehabil 25(2):387-393

27. Hurst NP, Kind P, Ruta D, Hunter M, Stubbings A (1997) Measuring health-related quality of life in rheumatoid arthritis: validity, responsiveness and reliability of EuroQol (EQ-5D). Br J Rheumatol 36(5):551-559

28. Obradovic M, Lal A, Liedgens H (2013) Validity and responsiveness of EuroQol-5 dimension (EQ-5D) versus Short Form-6 dimension (SF-6D) questionnaire in chronic pain. Health Qual Life Outcomes 11:110

29. Krabbe PF, Stouthard ME, Essink-Bot ML, Bonsel GJ (1999) The effect of adding a cognitive dimension to the EuroQol multiattribute health-status classification system. J Clin Epidemiol 52(4):293-301

30. Williams A (1990) EuroQol - a new facility for the measurement of health-related quality of life. Health Policy 16(3):199-208

31. Lamers LM, Stalmeier PF, McDonnell J, Krabbe PF, van Busschbach JJ (2005) Measuring the quality of life in economic evaluations: the Dutch EQ-5D tariff. Ned Tijdschr Geneeskd 149(28):1574-1578

32. Gandek B, Ware JE, Aaronson NK, Apolone G, Bjorner JB, Brazier JE et al (1998) Cross-validation of item selection and scoring for the SF-12 Health Survey in nine countries: results from the IQOLA Project. J Clin Epidemiol 51:1171-1178

33. Hoeymans N, van Lindert H, Westert GP (2005) The health status of the Dutch population as assessed by the EQ-6D. Qual Life Res 14(3):655-663

34. Kind P, Dolan P, Gudex C, Williams A (1998) Variations in population health status: results from a United Kingdom national questionnaire survey. BMJ 316(7133):736-741

35. Dawson J, Boller I, Doll H, Lavis G, Sharp RJ, Cooke P, Jenkinson C (2012) Factors associated with patient satisfaction with foot and ankle surgery in a large prospective study. Foot (Edinb) 22(3):211218

36. Su Y, Chen W, Zhang T, Wu X, Wu Z, Zhang Y (2013) Bohler's angle's role in assessing the injury severity and functional outcome of internal fixation for displaced intra-articular calcaneal fractures: a retrospective study. BMC Surg 13:40

37. Sayed-Noor AS, Agren PH, Wretenberg P (2011) Interobserver reliability and intraobserver reproducibility of three radiological classification systems for intra-articular calcaneal fractures. Foot Ankle Int 32:861-866

38. Bhattacharya R, Vassan UT, Finn P, Port A (2005) Sanders classification of fractures of the os calcis. An analysis of inter- and intraobserver variability. J Bone Joint Surg Br 87(2):205-208

39. Humphrey CA, Dirschl DR, Ellis TJ (2005) Interobserver reliability of a CT-based fracture classification system. J Orthop Trauma 19(9):616-622

40. Otero JE, Westerlind BO, Tantavisut S, Karam MD, Phisitkul P, Akoh CC, Gao Y, Marsh JL (2015) There is poor reliability of Böhler's angle and the crucial angle of Gissane in assessing displaced intra-articular calcaneal fractures. Foot Ankle Surg 21(4):277-281

41. Ebraheim NA, Elgafy H, Sabry FF, Freih M, Abou-Chakra IS (2000) Sinus tarsi approach with trans-articular fixation for displaced intra-articular fractures of the calcaneus. Foot Ankle Int 21(2): 105-113

42. Leung KS, Yuen KM, Chan WS (1993) Operative treatment of displaced intra-articular fractures of the calcaneum. Medium-term results. J Bone Joint Surg Br 75(2):196-201

43. Kinner B, Schieder S, Müller F, Pannek A, Roll C (2010) Calcaneocuboid joint involvement in calcaneal fractures. J Trauma 68(5):1192-1199

44. Alexandridis G, Gunning AC, Leenen LP (2016) Health-related quality of life in trauma patients who sustained a calcaneal fracture. Injury 47(7):1586-1591

45. Kristman V, Manno M, Côté P (2004) Loss to follow-up in cohort studies: how much is too much? Eur J Epidemiol 19(8):751-760 